\title{
Blood parasites in Passeriformes in central Germany: Prevalence and lineage diversity of Haemosporida (Haemoproteus, Plasmodium and Leucocytozoon) in six common songbirds
}

\author{
Yvonne R. Schumm ${ }^{\text {Corresp.. }}{ }^{1}$ ， Christine Wecker ${ }^{1}$, Carina Marek ${ }^{1}$, Mareike Wassmuth ${ }^{1}$, Anna Bentele ${ }^{1}$, \\ Hermann Willems ${ }^{2}$, Gerald Reiner ${ }^{2}$, Petra Quillfeldt ${ }^{1}$ \\ ${ }^{1}$ Department of Animal Ecology \& Systematics, Justus Liebig University, Giessen, Germany \\ 2 Department of Clinical Veterinary Sciences, Justus Liebig University, Giessen, Germany \\ Corresponding Author: Yvonne R. Schumm \\ Email address: Yvonne.R.Schumm@bio.uni-giessen.de
}

Background: Avian Haemosporida are vector-borne parasites that commonly infect Passeriformes. Molecular analyses revealed a high number of different lineages and lineage specific traits like prevalence and host-specificity, but knowledge of parasite prevalence and lineage diversity in wild birds in Central Germany is still lacking.

Results: Blood samples from a total of 238 adult and 122 nestling songbirds belonging to six species were investigated for infections with avian haemosporidian genera and lineages (Haemoproteus spp., Plasmodium spp., Leucocytozoon spp.) and Trypanosoma avium using PCR, targeting the parasite mitochondrial cytochrome $b$ gene and 18S ribosomal RNA. In total, the prevalence in adult birds was $31.3 \%$ infected with Haemoproteus, $12.5 \%$ with Plasmodium and $71.0 \%$ with Leucocytozoon (nestlings excluded). None of the tested birds was infected with Trypanosoma avium. Only in two nestling birds, aged 12-17 days, a Leucocytozoon spp. infection was proven. Among 225 successfully sequenced samples, we found four Haemoproteus, three Plasmodium and 19 Leucocytozoon lineages, including two new Leucocytozoon lineages. Furthermore, we report two new host-lineage associations.

Conclusions: As first study investigating avian haemosporidian parasites in Central Germany, we provide new information on genetic diversity of Haemosporida infecting Passeriformes. We show that even with a small sample size new lineages as well as previously unknown linkages between certain lineages and host species can be detected. This may help to elucidate the diversity of lineages as well as lineage-host-connections of avian Haemosporida. 
1 Blood parasites in Passeriformes in central Germany: Prevalence and lineage diversity of

2 Haemosporida (Haemoproteus, Plasmodium and Leucocytozoon) in six common songbirds

3

4 Authors: Yvonne R. Schumm ${ }^{1 *}$, Christine Wecker ${ }^{1}$, Carina Marek $^{1}$, Mareike Wassmuth ${ }^{1}$, Anna

5 Bentele ${ }^{1}$, Hermann Willems ${ }^{2}$, Gerald Reiner ${ }^{2}$ \& Petra Quillfeldt ${ }^{1}$

$6{ }^{1}$ Department of Animal Ecology \& Systematics, Justus Liebig University, Heinrich-Buff-Ring 26-

7 32, 35392 Giessen, Germany.

$8{ }^{2}$ Department of Clinical Veterinary Sciences, Justus Liebig University, Frankfurter Strasse 112, 935392 Giessen, Germany.

* Corresponding author, Email address: Yvonne.R.Schumm@bio.uni-giessen.de

\section{Abstract}

Background: Avian Haemosporida are vector-borne parasites that commonly infect Passeriformes. Molecular analyses revealed a high number of different lineages and lineage specific traits like prevalence and host-specificity, but knowledge of parasite prevalence and lineage diversity in wild birds in Central Germany is still lacking.

Results: Blood samples from a total of 238 adult and 122 nestling songbirds belonging to six species were investigated for infections with avian haemosporidian genera and lineages (Haemoproteus spp., Plasmodium spp., Leucocytozoon spp.) and Trypanosoma avium using PCR, targeting the parasite mitochondrial cytochrome $b$ gene and $18 \mathrm{~S}$ ribosomal RNA. In total, the prevalence in adult birds was 31.3\% infected with Haemoproteus, $12.5 \%$ with Plasmodium and 71.0\% with Leucocytozoon (nestlings excluded). None of the tested birds was infected with Trypanosoma avium. Only in two nestling birds, aged 12-17 days, a Leucocytozoon spp. infection was proven. Among 225 successfully sequenced samples, we found four Haemoproteus, three Plasmodium and 19 Leucocytozoon lineages, including two new Leucocytozoon lineages. Furthermore, we report two new host-lineage associations. Conclusions: As first study investigating avian haemosporidian parasites in Central Germany, we provide new information on genetic diversity of Haemosporida infecting Passeriformes. We show that even with a small sample size new lineages as well as previously unknown linkages 
29 between certain lineages and host species can be detected. This may help to elucidate the 30 diversity of lineages as well as lineage-host-connections of avian Haemosporida. 
31

32

33

34

\section{Introduction}

Avian blood parasites (Hematozoa) infect both domestic and wild birds, and therefore they have been objects of intensive scientific research over a long period (Valkiūnas, 1996; Valkiūnas, 2005; Bensch et al., 2013). Among the most common blood parasite orders are the Haemosporida. These include among others the avian malaria-like genera Haemoproteus and Leucocytozoon as well as the pathogen of avian malaria Plasmodium. These avian Haemosporida belonging to the phylum Apicomplexa share a similar but complex life cycle (Schmid et al., 2017), including asexual stages of reproduction in a bird host and sexual stages within a vector (Valkiūnas, 2005; Santiago-Alarcon et al., 2012). Another common blood parasite is Trypanosoma avium, flagellate protozoans living in the bloodstream of birds (Hamilton et al., 2007). Hematophagous dipterans are the vectors of these parasites. Leucocytozoon parasites are vectored by blood-sucking dipterans of two families: black flies (Simuliidae) and biting midges (Ceratopogonidae) (Freund et al., 2016; Lotta et al., 2016). Ceratopogonid midges are also vectors for Haemoproteus spp. (Desser \& Bennett, 1993). The main vectors for Plasmodium spp. are several species of mosquitos (Culicidae) (Medeiros et al., 2013). The transmission for T. avium remains still unclear with various blood-sucking insects mentioned as possible vectors (Votypka et al., 2002). Haemosporida are generally considered as pathogens with a low pathogenicity and harmless in bird populations (Wiersch et al., 2007; Ciloglu et al., 2016), but several studies demonstrated different costs on life-history traits associated with Haemosporida infections: Haemosporidian parasites can affect the body condition (Valkiūnas et al., 2006), reproductive success (e.g. Hunter et al., 1997; Merino et al., 2000; Marzal et al., 2005; Tomás et al., 2007a; Knowles et al., 2010) and the survival (e.g. Dawson \& Bortolotti, 2000; Møller \& Nielsen, 2007; Donovan et al., 2008; Bueno et al., 2010). Haemosporida are abundant in many avian families and occur worldwide except in Antarctica (Valkiūnas, 2005; Bensch et al., 2009; Clark et al., 2014; Vanstreels et al., 2014). However, there are interspecific differences in the parasite prevalence (e.g. Bennett et al., 1993a, b; Valkiūnas, 2005) and in some orders, e.g. Passeriformes, the parasites are more abundant (Valkiūnas, 2005). On the basis of recent molecular studies, the diversity of Haemosporida species and lineages may be assessed more precisely. The species diversity 
60

61

62

63

64

65

66

67

68

69

seems to be as high as the diversity of avian species (Bensch et al., 2004) or even higher (Schmid et al., 2017) and thousands of lineages may exist (Szöllősi et al., 2011). Lineages can differ from each other in only one single nucleotide (e.g. one substitution) of the mitochondrial cytochrome b gene (Bensch et al., 2004; Hellgren et al., 2004; Bensch et al., 2009; Chagas et al., 2017). For the order Passeriformes alone, 912 Haemoproteus, 852 Plasmodium and 600 Leucocytozoon lineages are deposited in the avian haemosporidian parasite database MalAvi (Bensch et al. 2009, MalAvi database accessed August 2018). In addition, molecular surveys vastly improved our understanding about the host specificity of avian haemosporidian infections (Ciloglu et al., 2016). The Haemosporida occupy niches that vary from extreme host generalization to extreme host specialization (Okanga et al., 2014). Generally, Plasmodium spp. is known to be more host-generalized (e.g. Waldenström et al., 2002; Križanauskienè et al., 2006; Dimitrov et al., 2010; Mata et al., 2015), whereas species of Leucocytozoon as well as Haemoproteus are considered to be more host-specific (e.g. Waldenström et al., 2002; Beadell et al., 2004; Forrester \& Greiner, 2008; Dimitrov et al., 2010; Jenkins \& Owens, 2011). Trypanosoma avium seems to possess a relatively low host-specificity (Bennett et al., 1994; Sehgal et al., 2001).

Furthermore, prevalence varies not merely interspecific but also with the age of the birds. A common pattern observed in host-parasite assemblages is a higher abundance of parasites in juvenile compared to adult birds (Sol et al. 2003). However, for blue tits nesting in nest boxes, blood parasites are far less prevalent in nestlings than in adult birds (Cosgrove et al., 2006; Martinez-de la Puente et al., 2013). Possibly because box-nesting species may be shielded from vector exposure due to their enclosed surroundings (Dunn et al., 2017).

The aims of the present study were (i) to assess the prevalence of the Haemosporida: Plasmodium, Haemoproteus and Leucocytozoon as well as T. avium in six species of wild Passeriformes in Central Germany, (ii) to identify and compare the lineage diversity among the birds and to record interspecific-shared lineages by means of mitochondrial cytochrome $b$ sequencing as well as (iii) to compare the prevalence in adult and nestling birds.

\section{Material \& Methods}

\section{Origin and preparation of the samples}


89

90

91

92

93

94

95

96

97

98

Bird capture and sampling were carried out under license (Animal welfare officer of the University of Giessen, no. 662_GP and 828_GP, and the Regierungspräsidium Giessen, no. 1092012 and 77-2016) in accordance with the German legislation. Blood samples from 360 Passeriformes of four families and six species (blue tit Cyanistes caeruleus, Paridae; great tit Parus major, Paridae; coal tit Periparus ater, Paridae; eurasian tree sparrow Passer montanus, Passeridae; european pied flycatcher Ficedula hypoleuca, Muscicapidae and eurasian nuthatch Sitta europaea, Sittidae) were collected during April to June in the years 2015, 2017 and 2018 (Table 1).

Sample sites were located in and closely around the city Giessen ( $50^{\circ} 35^{\prime} 2.584^{\prime \prime} \mathrm{N}$ $8^{\circ} 40^{\prime} 42.251^{\prime \prime} \mathrm{E}$, Hesse, central Germany). All birds were captured at their nest boxes by hand and blood-sampled by brachial venipuncture. The blood was stored on Whatman FTA classic cards (Whatman ${ }^{\circledR}$, UK). For DNA isolation a $3 \times 3 \mathrm{~mm}$ piece of each sample was cut out of the FTA card with a sterile scalpel blade. Subsequently the DNA was extracted according to the ammonium-acetate protocol by Martinez et al. (2009) and purified with NZYspintech-columns (NZYTech, Lda.-Genes \& Enzymes, Portugal) or Zymo-Spin ${ }^{\mathrm{TM}}$ IIC columns (Zymo Research, USA). The presence and concentration of DNA were confirmed and determined with NanoDrop2000c UV-Vis Spectrophotometer (NanoDrop Technologies, USA). If the DNA concentration was higher than $80 \mathrm{ng} / \mu \mathrm{l}$, samples were diluted to $30 \mathrm{ng} / \mu \mathrm{l}$.

\section{Parasite screening}

A partial amplification of the mitochondrial cytochrome b gene of the different Haemosporida was accomplished by polymerase chain reaction (PCR) with the respective primers (Table 2).

For the detection of Haemoproteus/Plasmodium species the primer pair HaemF (5'ATGGTGCTTTCGATATATGCATG -3') and HaemR2 (5'- GCATTATCTGGATGTGATAATGGT -3')

(Bensch et al., 2000) was used. For Leucocytozoon detection we applied primer pair HaemFL (5'ATGGTGTTTTAGATACTTACATT -3') and HaemNR3 (5'- ATAGAAAGATAAGAAATACCATTC -3') (Hellgren et al., 2004). To check T. avium infections the accomplished primer pair was TryF (5'ATGCACTAGGCACCGTCG -3') and TryR (5'- GGAGAGGGAGCCTGAGAAATA -3') (Martinez-de la Puente et al., 2013) targeting the 18 S ribosomal RNA (Table 2). 
Nestlings were only checked for possible Leucocytozoon spp. and T. avium infections.

118 The PCR reactions with HaemF and HaemR2 consisted of $20 \mu \mathrm{l}$ reaction volumes containing $2 \mu \mathrm{l}$

119 DNA template $(14.2-80 \mathrm{ng} / \mu \mathrm{l}), 1.2 \mu \mathrm{l}$ of each primer $(10 \mu \mathrm{M}), 10 \mu \mathrm{l}$ of InnuMix PCR Master Mix

120 (2x, Analytik Jena AG, Germany) and $5.6 \mu$ l nuclease-free water. The PCR reaction for the 121 detection of Leucocytozoon spp. contained $2.5 \mu \mathrm{l}$ DNA template $(8.0-80 \mathrm{ng} / \mu \mathrm{l}), 0.6 \mu \mathrm{l}$ of each

$122 \operatorname{primer}(20 \mu \mathrm{M}), 10.6 \mu \mathrm{l}$ InnuMix PCR Master Mix and $5.7 \mu$ l nuclease-free water. For T. avium

123 evidence the PCR reaction volume was $20 \mu \mathrm{l}$ consisting of $2.5 \mu \mathrm{l}$ DNA template, $0.6 \mu \mathrm{l}$ of each

124 primer $(20 \mu \mathrm{M}), 10.6 \mu$ I DreamTaq PCR Master Mix (Thermo Fisher Scientific, Germany) and

$1255.7 \mu \mathrm{l}$ nuclease-free water. The PCR reaction parameters using thermal cyclers peqSTAR 96Q

126 (Peqlab, Germany) and Tone (Biometra, Germany) are given in Table 2. A positive as well as a

127 negative control were included in each run to ensure PCR was working properly. PCR amplicons

128 were visualized using QIAxcel Advanced (Qiagen, Switzerland) high-resolution capillary gel

129 electrophoresis. Samples rendering a clear peak during gel electrophoresis were Sanger

130 sequenced bi-directional by Microsynth-Seqlab (Sequence Laboratories Goettingen GmbH,

131 Germany).

$\underline{\text { Phylogenetic and statistical analyses }}$

133

134

135

136

137

138

139

140

141

142

143

144

The forward and reverse sequences were assembled and trimmed in CLC Main Workbench 7.6.4 (CLC Bio, Qiagen, Denmark). PCR and sequencing were repeated, if not all nucleotides of a sequence could be determined unambiguously. Sequences were excluded from network construction when repetitions did not improve sequence quality.

The consensus sequences were assigned to a parasite lineage by BLAST (BLASTN 2.3.0+, Zhang, 2000) using the database MalAvi (Bensch et al., 2009). Constructions of lineage networks for each Haemosporida genus, using the median-joining network method, were performed with PopART 1.7 (Bandelt et al., 1999; Leigh \& Bryant, 2015) after aligning the sequences in BioEdit v7.2.5 (Hall, 1999). For these alignments, we used 123 Leucocytozoon (478 bp), 39 Haemoproteus (463 bp) and 14 Plasmodium consensus sequences (440 bp). Statistical evaluation of comparing prevalences and number of interspecific shared lineages per genus was performed with R (R Development Core Team 2013) using the R 
145 Package R commander. To compare the equality of proportions of parameters mentioned 146 above the frequency distribution test Pearson`s Chi²-test was applied. A significance level of $147 \mathrm{p}<0.05$ was used.

148 Results

149 Blood parasite prevalence

150 We detected three Haemosporida parasite genera in the local bird population in and around 151 Giessen. The overall prevalence was 31.3\% for Haemoproteus, 12.5\% for Plasmodium and $15271.0 \%$ for Leucocytozoon (nestlings excluded) (Table 3). Only blue tits and great tits were 153 infected with all three genera. Coal tits were infected with Plasmodium and Leucocytozoon and

154 tree sparrows with Plasmodium and Haemoproteus. Nuthatches showed infections with Haemoproteus and Leucocytozoon. For pied flycatchers we only found evidence of Haemoproteus infections (Table 3).

Prevalence rates of Leucocytozoon spp. were highest in blue tits (94.8\%). The highest prevalence of Plasmodium infections occurred in coal tits (25.0\%). Haemoproteus was almost equally common in blue tits (36.2\%) and great tits (40.6\%) (Table 3). The prevalence for the three haemosporidian genera in adult birds was different between the genera (Pearson `s Chi test: $\left.\chi^{2}=129.1, d f=2, p<0.001\right)$. Comparing the prevalence of Haemoproteus and Plasmodium, Haemoproteus spp. was more prevalent significant (Pearson`s Chi $^{2}$-test: $\chi^{2}=13.2$, $\mathrm{df}=1, \mathrm{p}<0.001$ ), and Leucocytozoon was significantly more prevalent than the other two genera (Pearson`s Chi²-test: Haemoproteus/Leucocytozoon: $\chi^{2}=53.7, \mathrm{df}=1, \mathrm{p}<0.001$; Plasmodium/Leucocytozoon: $\chi^{2}=114.0, \mathrm{df}=1, \mathrm{p}<0.001$ ). For none of the tested birds a $T$. avium infection was detected. In blue tit nestlings a haemosporidian infection could not be detected by PCR. In great tit nestlings we proved an infection with Leucocytozoon, although the prevalence with $3.5 \%$ tits infected (2 out of 57 nestlings) was low.

\section{Lineage diversity}

In total, 26 haemosporidian lineages could be identified in the MalAvi database. We found four Haemoproteus spp., three Plasmodium spp. and 19 Leucocytozoon spp. lineages (Table 4). Great and blue tits showed similar high lineage diversities ( $n=15$ lineages: 2 Haemoproteus, 1 
173 Plasmodium and 12 Leucocytozoon lineages; $\mathrm{n}=17: 1$ Haemoproteus, 3 Plasmodium and 13

174 Leucocytozoon lineages, respectively). We identified two new Leucocytozoon lineages

175 (CYACAE02, GenBank accession number MH758695 and CYACAE03, MH758696) infecting blue

176 tits which differ each in $0.21 \%$ (1 nucleotide) from their closest MalAvi match. For new lineages

177 PCR and sequencing were performed twice to verify the results.

178 The lineage diversity of the other four species was less pronounced probably due to 179 smaller sample sizes. For pied flycatchers we detected one Haemoproteus lineage (PFC1). For

180 tree sparrows we found three lineages (1 Haemoproteus: PADOM03 and 2 Plasmodium: GRW11

181 and SGS1), for coal tits one lineage each for Plasmodium (TURDUS1) and Leucocytozoon

182 (PARUS19) and for nuthatches one Haemoproteus (PARUS1) and two Leucocytozoon lineages 183 (PARUS7 and PARUS20).

184 Several sequences $(n=11)$ could not be assigned to a single reference sequence due to 185 an insufficient sequence length or quality. In these cases, the sequences were determined to 186 the closest related reference lineages (Table S1).

\section{Host specificity}

188 Maximally three out of six Passeriformes species were found infected with the same lineage 189 (Table 4). We recorded the highest number of lineages occurring in several host species for Plasmodium. According to the BLAST results, all identified Plasmodium lineages occurred in more than one species (Table 4). In contrast, smaller percentages of lineages infecting more than one host species, were found for Leucocytozoon $(36.8 \%$ of the lineages infected two host species and only 5.3\% (one lineage: PARUS19) infected three host species) and Haemoproteus with 25\% (only one lineage (PARUS1) infected more than one host species) (Table 4). The difference in the percentage of interspecific shared lineages was not significant between the three Haemosporida genera (Pearson`s Chi ${ }^{2}$-test: $\chi^{2}=6.82, d f=4, p=0.15$ ).

Lineage Networks

The networks for each haemosporidian genus revealed the occurrence of four lineages for Haemoproteus (Fig. 1), three for Plasmodium (Fig. 2) and 18 for Leucocytozoon (Fig. 3). In the 
201 (C. caeruleus) occurred each separately from all the other sequences and had a BLAST of 202 maximum 99\% match with lineages deposit in MalAvi, indicating a different, new lineage 203 (named CYACAEO2 and CYACAE03). The genetic divergence to the closest MalAvi match of 204 CYACAE02 (sample NK17_P01) is 0.21\% (1 nucleotide difference to PARUS22, HM234031). The 205 difference of CYACAE03 (sample NK17_Y40) to its closest related match PARUS19 (99\% match 206 in $477 \mathrm{bp}$ ) is $0.21 \%$. The genetic divergence for the Leucocytozoon lineages in the network was $2070.21-7.95 \%$. All found lineages of the dataset are separated at least by one mutation 208 (equivalent to one hatch mark in the network). With the exception of PARUS19 and PARUS74 209 (Fig. 3). The mutation differentiating these lineages is located in the cytochrome b gene before 210 the fragment we used for network construction.

211 The Haemoproteus network (Fig. 1) shows that the lineage PFC1 (H. pallidus), occurring in all 212 three positively tested pied flycatchers, and the lineage PADOM03, found in one tree sparrow, 213 are clearly separated from the other Haemoproteus spp. lineages. Haemoproteus lineages had a 214 genetic divergence of $1.08-5.18 \%$. The Plasmodium network (Fig. 2) illustrates the three 215 lineages (SGS1, GRW11 and TURDUS1) found in this study. The results of this network lead to 216 the assumption that TURDUS1 exclusively infects coal tits. However, it must be noted that also 217 a blue tit was infected with TURDUS1, but the sample sequence was too short to be used for 218 the alignment. Plasmodium lineages in the network ranged from $0.23-4.32 \%$ in their genetic 219 divergence.

220

221

222

223

224

225

226

227

\section{$\underline{\text { Discussion }}$}

\section{$\underline{\text { Prevalence in nestling birds }}$}

Contrary to a high percentage of adult blue and great tits infected with at least one haemosporidian parasite we did not detect a single haemosporidian or T. avium infection in nestling blue tits and a very low infection rate of Leucocytozoon spp. in great tit nestlings. Generally, nestlings should be highly susceptible to vector-borne infection diseases due to their confinement to the nest, nakedness and immunological naivety during nestling period (Baker, 1975). Possibly, more nestlings might have been infected in our study, but our methodology did not accomplish detection if the disease was still at the prepatent stage. Infections cannot be 
229

230

231

232

233

234

235

236

237

238

239

240

241

242

243

244

245

246

247

248

249

250

251

252

253

254

255

256

detected immediately after transmission because of the prepatency period (i.e. the period between initial infection and the release of gametocytes into the peripheral blood). We can distinguish between parasites with shorter prepatency periods like Leucocytozoon (5 to 6 days) (Desser \& Bennett, 1993) or T. avium (24 to 48 hours) (Bennett, 1970), and with longer prepatency periods like Haemoproteus or Plasmodium. The period for Haemoproteus spp. varies from 11 to 21 days, for Plasmodium it can last from few days up to more than one month until an infection is detectable in the peripheral blood, depending on host and parasite species (Valkiūnas, 2005; Cosgrove et al., 2006). Alternatively, it could simply mean that the nestlings had not been infected yet.

To test if an infection was transmitted already, it would have been necessary to remove nestlings from their nests, raising them in vector-free cages and checking regularly for subsequent development of patent infections. Valkiūnas (2005) applied this approach in chaffinch (Fringilla coelebs) nestlings. In his study, only two out of 67 chicks (3\%), removed from the nest at 6 to 12 days of age, subsequently developed infections. Contrary, the infection rate of 25 to 50 day old wild fledglings was $36.2 \%$, suggesting that most infections occurred after the nestlings had left the nest (Valkiūnas, 2005). The very low rate of infections in nestling tits in our study might also result from a lack of vector activity during the nestling period as in northern temperature climes dipteran vector populations reach their peak not until late summer (Beaudoin et al., 1971).

\section{$\underline{\text { Prevalence in adult birds }}$}

Within Germany, only a few studies deal with the prevalence and distribution of infections with avian haemosporidian parasites (microscopic examination: Haberkorn, 1984; Krone et al., 2001; PCR-based methods: Wiersch et al., 2007; Jenkins \& Owens, 2011; Santiago-Alarcon et al., 2016) (see Table 5 for an overview of prevalences in great and blue tits sampled in Germany). Wiersch et al. (2007) sampled birds in the northern part of Germany. Infection prevalences in great tits were $30.4 \%$ for Haemoproteus and $46.4 \%$ for Plasmodium. In line with the present study, coal tits had no infections with Haemoproteus spp. and a similar infection rate with Plasmodium spp. (18.7\%). The infection rate for pied flycatchers with Haemoproteus spp. (0.9\%) 
257 was less than in the present study (21.4\%). In contrast to our findings, Wiersch et al. (2007)

258 reported Plasmodium infections in pied flycatchers (5.9\%). Santiago-Alarcon et al. (2016) found

259 no haemosporidian infection in eurasian nuthatches in Germany (20.0\% Haemoproteus spp.

260 and 30.0\% Leucocytozoon spp. in the present study) and Haberkorn (1984) found no

261 haemosporidian infections in coal tits (25.0\% Plasmodium spp. and 25.0\% Leucocytozoon spp. in

262 this study). As far as we know, no other data are available for european tree sparrow infection

263 rates in Germany.

264 In contrast to our results, low infection rates in blood smears from great tits were reported by

265 Haberkorn (1984) (Haemoproteus spp.: 7.3\%, Leucocytozoon spp.: 1.2\%). These variations in

266 prevalences might be based on methodological differences.

267 Jenkins \& Owens (2011) recorded 33\% Leucocytozoon prevalence in south Germany for great

268 tits and $50 \%$ for blue tits, which is much lower than the prevalences reported here for the two

269 species (77.3\% and 94.8\%, respectively). However, some studies report even higher prevalences

270 especially for the avian malaria pathogen Plasmodium (e.g. 91\% for blue tits from Switzerland,

271 Glaizot et al., 2012; 100\% in a blue tits population in England, Szöllősi et al., 2011) and for T.

272 avium (e.g. 49\% of infected blue tits in Spain, Fargallo \& Merino, 2004; 40\% in female blue tits

273 in Spain, Tomás et al., 2007b).

274 However, it should be considered that sensitive PCR-based diagnostics are able to detect

275 sporozoites of Leucocytozoon in the peripheral blood (Valkiūnas et al., 2009). Sporozoites are

276 transmitted to the bird during the blood meal of the vector fly. As it is unclear whether all of

277 these sporozoites result in an actual infection of the host, the evidence of haemosporidian

278 lineages by PCR based method does not necessarily allow the conclusion that the parasites

279 complete their entire life cycle in the host (Valkiūnas et al., 2009).

280 The high prevalence of Leucocytozoon spp. in blue and great tits in this study compared

281 to the parasite genera Plasmodium and Haemoproteus may be associated with the vector

282 abundance and behavior. Dipteran vectors of some Haemosporida genera may be more strictly

283 ornithophilic than Culicidae vectors of Plasmodium spp., which feed on a broader range of

284 vertebrates, reducing their potential for transmitting diseases to birds (Savage et al., 2009). The

285 reasons for the high Leucocytozoon prevalence in our study area Hesse compared to other parts 
286 of Germany are speculative. One reason might be that Hesse is the most richly forested of all

287 German states (42\% of the state area are forests) (Forest report Hesse, 2015). Moreover, these

288 forest sites are mostly near-natural and with a lot of woodland-running-waters, that are mostly

289 (70\%) in a good ecological condition (Forest report Hesse, 2015). As Simuliidae, the vectors of

290 all Leucocytozoon species (except L. caulleryi, that is vectored by a biting midge; Lotta et al.,

291 2016), need running waters for reproduction (Lacey \& Merrit, 2003) the conditions for their

292 reproduction in Hesse are good according to the habitat parameters mentioned above.

293 However, we did not record any habitat parameters during our study and similarly no

294 nationwide data throughout Germany on black fly distribution is available at the moment.

295 Therefore, it is not possible to test regional prevalence of Leucocytozoon depending on the

296 distribution and density of black flies so far.

297 Unfortunately, many studies do not consider all three avian haemosporidian genera and

298 especially Leucocytozoon is underrepresented in the literature (van Rooyen et al., 2013a).

299 Hence, a detailed comparison of prevalences in different avian hosts is difficult to assess.

300 However, comparison of our results with studies from Germany and Europe show that the

301 prevalences of avian haemosporidian infections differ among local bird populations (e.g.

302 Haberkorn, 1984; Wiersch et al., 2007; Santiago-Alarcon et al., 2016). The factors causing these

303 local differences are still poorly understood. Szöllősi et al. (2011) showed that the distribution

304 and prevalence of avian malarial parasite species are influenced by multiple factors, such as

305 host and dipteran vector density, habitat characteristics or climatic conditions (see also Wood

306 et al., 2007; Merino et al., 2008). Moreover, prevalence seems to be a lineage-specific trait

307 (Szöllősi et al., 2011). That shows the importance to investigate not only prevalence for the

308 parasite genera, but rather identify the different parasite lineages infecting regional bird

309 populations.

310 Lineage diversity and host specificity

311 By using molecular phylogeny, we detected different lineages for each parasite genus. Few

312 lineages differed by only one nucleotide, resulting in low genetic divergences. Other authors

313 (e.g. Bensch et al., 2000; Chagas et al., 2017) also found low sequence divergences in 
314 Haemosporida. In this study, the two new Leucocytozoon lineages (CYACAE02 and CYACAE03)

315 differ in one nucleotide each from their closest matching lineage, indicating they may have 316 diverged only recently (Bensch et al., 2000).

317 The lineage PFC1 (H. pallidus), infecting only pied flycatchers in this study, is clearly

318

319

320

321

322

323

324

325

326

327

328

329

330

331

332

333

334

335

336

337

338

339

340

341

342

separated in the phylogenetic tree as well as in the network. It is possible that the infection with this lineage was transmitted outside Germany, as pied flycatchers, wintering in Africa, are the only long-distance migratory bird species in our study and infection with the PFC1 lineage might be vectored from dipteran vectors in Africa. However, the distribution of vectors on wintering and breeding grounds, especially for Haemoproteus, is poorly understood (Dubiec et al., 2017) and transmission of PFC1 lineage possibly also occurs in Europe (Jones, 2017).

Generally, host specificity of haemosporidian lineages differs among the genera with host specialists being predominant among Haemoproteus and Leucocytozoon lineages but being absent among Plasmodium lineages (Mata et al., 2015). This general pattern of host specificity, with Haemoproteus being the most host specialized and Plasmodium being more host generalized, is supported by several studies (e.g. Ricklefs \& Fallon, 2002; Waldenström et al., 2002; Križanauskienė et al., 2006; Dimitrov et al., 2010; Jenkins \& Owens, 2011; Drovetski et al., 2014; Okanga et al., 2014; Mata et al., 2015; Ciloglu et al., 2016). Less studies regarding host specificity of Leucocytozoon lineages exist, therefore it is necessary to do further investigations to confirm Leucocytozoon lineages to be, as assumed, host-specific mostly at avian order level and in some cases even on species level (Forrester \& Greiner, 2008; Ciloglu et al., 2016). In the present study, we found no significant difference in the host specificity of the three haemosporidian genera. But due to small sample sizes and closely related host species (all within the order Passeriformes) general patterns should be proven with a higher number of samples and an increased range of species.

Our data complements existing knowledge about host specificity and distribution of some individual lineages as we obtained first records for lineages infecting a specific host species. The two Leucocytozoon lineages PARUS20 (isolated from sample NK17_C05, MH758693) and PARUS7 (isolated from samples NK17_C04, MH758692 and NK17_C14, MH758694) were not detected in eurasian nuthatches (S. europaea) prior to this study (Bensch 
343

344

345

346

347

348

349

350

351

352

353

354

355

356

357

358

359

360

361

362

363

364

365

366

367

368

369

et al. 2009, MalAvi database accessed August 2018). This is also the first record of the PARUS7 lineage in the family Sittidae. Host specificity seems not to be determined by parasite genera but by the single lineages comparable with the lineage-specific prevalences. For example, several studies (e.g. Ricklefs \& Fallon, 2002; Beadell et al., 2009; Loiseau et al., 2012) suggest that few lineages of avian malaria pathogen Plasmodium exhibit extreme generalization, whereas other lineages seem to be constrained to certain host families or even host species. Host shifts are often associated with a change in pathogen virulence (Toft \& Karter, 1990). Therefore, invading a new host may increase or decrease parasite virulence (Bull, 1994). This might be the case for the two Leucocytozoon lineages (PARUS20 and PARUS7) infecting nuthatches.

\section{Conclusion}

In summary, we found avian malaria and avian malaria-like pathogens of three genera (Plasmodium, Haemoproteus and Leucocytozoon) infecting common Passeriformes in Central Germany. The findings presented here provide knowledge about the distribution and prevalence of avian haemosporidian parasites in a geographic region, which has not yet been subject to studies investigating this kind of parasites. On the basis of a relatively small sample size we found numerous lineages and detected several first records of lineage infections as well as two new Leucocytozoon lineages. Comparison with studies from other parts of Germany pointed out regional differences in Haemosporida prevalence, in particular for Leucocytozoon. Understanding these patterns resulting in regional differences could be important in future to understand the epidemiology of blood parasites in wild bird populations.

\section{Acknowledgements}

We would like to thank Wendy Gibson (School of Biological Sciences, University of Bristol) and Rasa Bernotienè (Nature Research Center, Vilnius) for trypanosome infected bird samples used as positive controls. We thank all helpers of the nest box checks in 2015 (Jennifer Schwarz, David Ensslin and Carsten Hoth) and 2017/18 (Anna Bentele, Fabian Gausepohl, Benjamin Grünwald, Daniel Höhn and Michael Reis) and Tobias Warmann for labwork assistance. 


\section{References}

371

372

373

374

375

376

377

378

379

380

381

382

383

384

385

386

387

388

389

390

391

392

393

394

395

396

397

398

399

400

401

402

403

404

405

406

407

408

409

410

411

412

Baker JR. 1975. Epizootiology of some haematozoic protozoa of English birds. Journal of Natural History 9:601-609.

Bandelt H, Forster P, Röhl A. 1999. Median-joining networks for inferring intraspecific phylogenies. Molecular Biology and Evolution 16:37-48.

Beadell JS, Gering E, Austin J, Dumbacher JP, Peirce MA, Pratt TK, Atkinson CT, Fleischer RC. 2004. Prevalence and differential host-specificity of two avian blood parasite genera in the Australo-Papuan region. Molecular Ecology 13:3829-3844.

Beadell JS, Covas R, Gebhard C, Ishtiaq F, Melo M, Schmidt BK, Perkins S, Graves GR, Fleischer R. 2009. Host associations and evolutionary relationships of avian blood parasites from West Africa. International Journal for Parasitology 39:257-266.

Beaudoin RL, Applegate JE, David DE, Mclean RG. 1971. A model for the ecology of avian malaria. Journal of Wildlife Diseases 7:5-13.

Bennett GF. 1970. Trypanosoma avium Danilewsky in the avian host. Canadian Journal of Zoology 48:803-807.

Bennett GF, Bishop MA, Peirce MA. 1993a. Checklist of the avian species of Plasmodium Marchiafava and Celli, 1885 (Apicomplexa) and their distribution by avian family and Wallacean life zones. Systematic Parasitology 26:171-179.

Bennett GF, Peirce MA, Ashford RW 1993b. Avian haematozoa: mortality and pathogenicity. Journal of Natural History 27:993-1001.

Bennett GF, Earle RA, Squires-Parsons D. 1994. Trypanosomes of some sub-Saharan birds. Onderstepoort Journal of Veterinary Research 61:263-271.

Bensch S, Stjernman M, Hasselquist H, Ostman O, Hansson B, Westerdahl H, Torres Pinheiro R. 2000. Host specificity in avian blood parasites: A study of Plasmodium and Haemoproteus mitochondrial DNA amplified from birds. Proceedings of the Royal Society of London Series B: Biological Sciences 267:1583-1589.

Bensch S, Perez-Tris J, Waldstrom J, Hellgren O. 2004. Linkage between nuclear and mitochondrial DNA sequences in avian malaria parasites: multiple cases of cryptic speciation? Evolution 58:1617-1621.

Bensch S, Hellgren O, Perez-Tris J. 2009. MalAvi: a public database of malaria parasites and related haemosporidians in avian hosts based on mitochondrial cytochrome $b$ lineages. Molecular ecology resources 9:1353-1358. 
413

414

415

416

417

418

419

420

421

422

423

424

425

426

427

428

429

430

431

432

433

434

435

436

437

438

439

440

441

442

443

444

445

446

447

448

449

450

451

452

453

454

455

456
Bensch S, Hellgren O, Križanauskienė A, Palinauskas V, Valkiūnas G, Outlaw D, Ricklefs RE. 2013. How can we determine the molecular clock of malaria parasites? Trends in Parasitology 29:363369.

Bueno MG, Lopez RP, de Menezes RM, Costa-Nascimento MdeJ, Lima GF, Araujo RA, Guida FJ, Kirchgatter K. 2010. Identification of Plasmodium relictum causing mortality in penguins (Spheniscus magellanicus) from Sao Paulo Zoo, Brazil. Veterinary Parasitology 173:123-127.

Bull JJ. 1994. Perspective-virulence. Evolution 48:1423-1437.

Chagas CRF, Valkiūnas G, Guimarães LdO, Monteiro EF, Guida FJV, Simões RF, Rodrigues PT, Luna EJdA, Kirchgatter K. 2017. Diversity and distribution of avian malaria and related haemosporidian parasites in captive birds from a Brazilian megalopolis. Malaria Journal 16:83 DOI: 10.1186/s12936-017-1729-8.

Ciloglu A, Yildirim A, Duzlu O, Onder Z, Dogan Z, Inci A. 2016. Investigation of avian haemosporidian parasites from raptor birds in Turkey, with molecular characterisation and microscopic confirmation. Folia Parasitologica 63 DOI: 10.14411/fp.2016.023.

Clark NJ, Clegg SM, Lima MR. 2014. A review of global diversity in avian haemosporidians (Plasmodium and Haemoproteus: Haemosporida): new insights from molecular data. International Journal for Parasitology 44:329-338.

Cosgrove CL, Knowles SCL, Day KP, Sheldon BC. 2006. No evidence for avian malaria infection during the nestling phase in a passerine bird. The Journal of Parasitology 92:1302-1304.

Dawson RD, Bortolotti GR. 2000. Effects of hematozoan parasites on condition and return rates of American Kestrels. The Auk: Ornithological Advances 117:373-380.

Desser SS, Bennett GF. 1993. The genera Leucocytozoon, Haemoproteus and Hepatocystis. In: Kreier JP, ed. Parasitic Protozoa. San Diego, California: Academic Press, 273-307.

Dimitrov D, Zehtindjiev P, Bensch S. 2010. Genetic diversity of avian blood parasites in SE Europe: cytochrome $b$ lineages of the genera Plasmodium and Haemoproteus (Haemosporida) from Bulgaria. Acta Parasitologica 55:201-209.

Donovan TA, Schrenzel M, Tucker TA, Pessier AP, Stalls IH. 2008. Hepatic hemorrhage, hemocoelom, and sudden death due to Haemoproteus infection in passerine birds: eleven cases. Journal of Veterinary Diagnostic Investigation 20:304-313.

Drovetski SV, Aghayan SA, Mata VA, Lopes RJ, Mode NA, Harvey JA, Voelker G. 2014. Does the niche breadth or trade-off hypothesis explain the abundance-occupancy relationship in avian Haemosporidia? Molecular ecology 23:3322-3329. 
457

458

459

460

461

462

463

464

465

466

467

468

469

470

471

472

473

474

475

476

477

478

479

480

481

482

483

484

485

486

487

488

489

490

491

492

493

494

495

496

497

498
Dubiec A, Podmokła E, Harnist I, Mazgajski TD. 2017. Haemoparasites of the pied flycatcher: inter-population variation in the prevalence and community composition. Parasitology 145:912919 DOI: $10.1017 /$ S0031182017001913.

Dunn JC, Stockdale JE, Bradford EL, McCubbin A, Morris AJ, Grice PV, Goodman SJ, Hamer KC. 2017. High rates of infection by blood parasites during the nestling phase in UK Columbids with notes on ecological associations. Parasitology 144:622-628.

Ejiri H, Sato Y, Kim KS, Hara T, Tsuda Y, Imura T, Murata K, Yukawa M. 2011. Entomological study on transmission of avian malaria parasites in a zoological garden in Japan: bloodmeal identification and detection of avian malaria parasite DNA from blood-fed mosquitoes. Journal of Medical Entomology 48:600-607.

Fargallo JA, Merino S. 2004. Clutch size and haemoparasite species richness in adult and nestling blue tits. Écoscience 11:168-174.

Forest report Hesse. 2015. Regionaler Waldbericht Hessen 2015. Regionale PEFC-Arbeitsgruppe Hessen e.V. (eds.). https://pefc.de/media/filer_public/c2/2d/c22d6ce7-3bcb-4580-aee1c465b85dd094/hessen_waldbericht_2015.pdf

Forrester DJ, Greiner EC. 2008. Leucocytozoonosis. In: Atkinson CT, Thomas NJ, Hunter DB, eds. Parasitic Diseases of Wild Birds. Ames, lowa: Blackwell Publishing, 54-107.

Freund D, Wheeler SS, Townsend AK, Boyce WM, Ernest HB, Cicero C, Sehgal RNM. 2016. Genetic sequence data reveals widespread sharing of Leucocytozoon lineages in corvids. Parasitology Research 115:3557-3565.

Glaizot O, Fumagalli L, Iritano K, Lalubin F, Van Rooyen J, Christe P. 2012. High Prevalence and Lineage Diversity of Avian Malaria in Wild Populations of Great Tits (Parus major) and Mosquitoes (Culex pipiens). PLoS One 7(4):e34964 DOI: 10.1371/journal.pone.0034964.

Haberkorn A. 1984. Observations on malaria in European perching birds (Passeriformes). Zentralblatt für Bakteriologie, Mikrobiologie und Hygiene Series A 256:288-295.

Hall TA. 1999. BioEdit: a user-friendly biological sequence alignment editor and analysis program for Windows 95/98/NT. Nucleic Acids Symposium 41:95-98.

Hamilton PB, Gibson WC, Stevens JR. 2007. Patterns of co-evolution between trypanosomes and their hosts deduced from ribosomal RNA and protein-coding gene phylogenies. Molecular Phylogenetics and Evolution 44:15-25. 
499

500

501

502

503

504

505

506

507

508

509

510

511

512

513

514

515

516

517

518

519

520

521

522

523

524

525

526

527

528

529

530

531

532

533

534

535

536

537

538

539

540

541

Hellgren O, Waldenström J, Bensch S 2004. A new PCR assay for simultaneous studies of Leucocytozoon, Plasmodium, and Haemoproteus from avian blood. Journal of Parasitology 90:797-802.

Hunter DB, Rohner C, Currie DC. 1997. Mortality in fledgling great horned owls from black fly hematophaga and leucocytozoonosis. Journal of Wildlife Diseases 33:486-491.

Jenkins T, Owens IP. 2011. Biogeography of avian blood parasites (Leucocytozoon spp.) in two resident hosts across Europe: phylogeographic structuring or the abundance-occupancy relationship? Molecular Ecology 20:3910-3920.

Jones W. 2017. Parasitism and speciation in a changing world. Introductory Research Essay No. 104, Uppsala University.

Knowles SCL, Palinauskas V, Sheldon BC. 2010. Chronic malaria infections increase family inequalities and reduce parental fitness: experimental evidence from a wild bird population. Journal of Evolutionary Biology 23:557-569.

Križanauskienė A, Hellgren O, Kosarev V, Sokolov L, Bensch S, Valkiūnas G. 2006. Variation in host specificity between species of avian hemosporidian parasites: evidence from parasite morphology and cytochrome B gene sequences. Journal of Parasitology 92:1319-1324.

Krone O, Priemer J, Streich J, Soemmer J, Langgemach T, Lessow O. 2001. Haemosporida of birds of prey and owls from Germany. Acta Protozoologica 40:281-289.

Lacey LA, Merritt RW. 2003. The Safety of Bacterial Microbial Agents Used for Black Fly and Mosquito Control in Aquatic Environments. In Hokkanen HMT, Hajek AE (eds.) Enviromental impacts of Microbial Insecticides. Progress in Biological Control, Volumne 1, Springer, Dordrecht.

Leigh JW, Bryant D. 2015. PopART: Full-feature software for haplotype network construction. Methods in Ecology and Evolution 6:1110-1116.

Loiseau C, Harrigan RJ, Robert A, Bowie RCK, Thomassen HA, Smith TB, Sehgal RNM. 2012. Host and habitat specialization of avian malaria in Africa. Molecular Ecology 21:431-441.

Lotta AL, Pacheco MA, Escalante AA, Gonzalez AD, Mantilla JS, Moncada LI, Adler PH, Matta NE. 2016. Leucocytozoon Diversity and Possible Vectors in the Neotropical highlands of Colombia. Protist 167:185-204.

MalAvi. A Database for avian haemosporidian parasites. Table: Host And Sites. Available at http://mbio-serv2.mbioekol.lu.se/Malavi/ (downloaded 09 August 2018, 3.25 PM). 
542 Martinez J, Martinez-de La Puente J, Herrero J, Del Cerro S, Lobato E, Aguilar JR, Vasquez RA, 543 Merino S. 2009. A restriction site to differentiate Plasmodium and Haemoproteus infections in 544 birds: on the inefficiency of general primers for detection of mixed infections. Parasitology 545 136:713-722.

546

547

548

549

550

551

552

553

554

555

556

557

558

559

560

561

562

563

564

565

566

567

568

569

570

571

572

573

574

575

576

577

578

579

580

581

582

583

584

585
Martinez-de la Puente J, Martinez J, Rivero-de Aguilar J, Del Cerro S, Merino S. 2013. Vector abundance determines Trypanosoma prevalence in nestling blue tits. Parasitology 140:10091015.

Marzal A, de Lope F, Navarro C, Moller AP. 2005. Malarial parasites decrease reproductive success: an experimental study in a passerine bird. Oecologia 142:541-545.

Mata VA, da Silva LP, Lopes RJ, Drovetski SV. 2015. The Strait of Gibraltar poses an effective barrier to host-specialised but not to host-generalised lineages of avian Haemosporidia. International Journal for Parasitology 45:711-719.

Medeiros MCl, Hamer GL, Ricklefs RE. 2013. Host compatibility rather than vector-hostencounter rate determines the host range of avian Plasmodium parasites. Proceedings of the royal society B 280:20122947 DOI: 10.1098/rspb.2012.2947.

Merino S, Moreno J, Sanz JJ, Arriero E. 2000. Are avian blood parasites pathogenic in the wild? A medication experiment in blue tits (Parus caeruleus). Proceedings of the Royal Society B 267:2507-2510.

Merino S, Moreno J, Vásquez RA, Martínez J, Sánchez-Monsálvez I, Estades CF, Ippi S, Sabat P, Rozzi R, McGehee S. 2008. Haematozoa in forest birds from southern Chile: latitudinal gradients in prevalence and parasite lineage richness. Austral Ecology 33:329-340.

Møller AP, Nielsen JT. 2007. Malaria and risk of predation: A comparative study of birds. Ecology: 88:871-881.

Okanga SM, Cumming GS, Hockey PAR, Nupen L, Peters JL. 2014. Host speciation and cospeciation in avian hemosporidia in the Western Cape, South Africa. PLoS One 9(2):e86382 DOI: 10.1371/journal.pone.0086382.

Perez-Tris J, Bensch S. 2005. Dispersal increases local transmission of avian malarial parasites. Ecology Letters 8:838-845.

Ricklefs RE, Fallon SM. 2002. Diversification and host switching in avian malaria parasites. Proceedings of the Royal Society B 269:885-892.

Santiago-Alarcon D, Palinauskas V, Schaefer HM. 2012. Diptera vectors of avian haemosporidian parasites: untangling parasite life cycles and their taxonomy. Biological Reviews of the Cambridge Philosophical Society 87:928-964. 
586

587

588

589

590

591

592

593

594

595

596

597

598

599

600

601

602

603

604

605

606

607

608

609

610

611

612

613

614

615

616

617

618

619

620

621

622

623

624

625

626

627

628
Santiago-Alarcon D, MacGregor-Fors I, Kühnert K, Segelbacher G, Schaefer HM. 2016. Avian haemosporidian parasites in an urban forest and their relationship to bird size and abundance. Urban Ecosystems 19:331-346.

Savage AF, Robert V, Goodman SM, Raharimanga V, Raherilalao MJ, Andrianarimisa A, Ariey F, Greiner EC. 2009. Blood parasites in birds from Madagascar. Journal of Wildlife Diseases 45:907-920.

Schmid S, Fachet K, Dinkel A, Mackenstedt U, Woog F. 2017. Carrion crows (Corvus corone) of southwest Germany: important hosts for haemosporidian parasites. Malaria Journal 16:369 DOI: 10.1186/s12936-017-2023-5.

Scordato ESC, Kardish MR. 2014. Prevalence and beta diversity in avian malaria communities: host species is a better predictor than geography. Journal of Animal Ecology 83:1387-1397.

Sehgal RNM, Jones HI, Smith TB. 2001. Host specificity and incidence of Trypanosoma in some African rainforest birds: a molecular approach. Molecular Ecology 10:2319-2327.

Sol D, Jovani R, Torres J. 2003. Parasite mediated mortality and host immune response explain age-related differences in blood parasitism in birds. Oecologia 135: 542-547.

Szöllősi E, Cichoń M, Eens M, Hasselquist D, Kempenaers B, Merino S, Nilsson JÅ, Rosivall B, Rytkönen S, Török J, Wood MJ, Garamszegi LZ. 2011. Determinants of distribution and prevalence of avian malaria in blue tit populations across Europe: separating host and parasite effects. Journal of Evolutionary Biology 24:2014-2024.

Toft CA, Krater AJ. 1990. Parasite-host coevolution. Trends in Ecology \& Evolution 5:326-329.

Tomás G, Merino S, Moreno J, Morales J, Martìnez-de la Puente J. 2007a. Impact of blood parasites on immunoglobulin level and parental effort: a medication field experiment on a wild passerine. Functional Ecology 21:125-133.

Tomás G, Merino S, Moreno J, Morales M. 2007b. Consequences of nest reuse for parasite burden and female health and condition in blue tits, Cyanistes caeruleus. Animal Behaviour 73:805-814.

Valkiūnas GA. 1996. Ecological implications of Hematozoa in birds. Bulletin for the Scandinavian Society for Parasitology 6:103-113.

Valkiūnas G. 2005. Avian Malaria Parasites and Other Haemosporidia. Boca Raton, Florida: CRC Press. 
629 Valkiūnas G, Zickus T, Shapoval AP, lezhova TA. 2006. Effect of Haemoproteus belopolskyi 630 (Haemosporida: Haemoproteidae) on body mass of the blackcap Sylvia atricapilla. Journal of 631 Parasitology 92:1123-1125.

632

633

634

635

636

637

638

639

640

641

642

643

644

645

646

647

648

649

650

651

652

653

654

655

656

657

658

659

660

661

662

663

664

665

666

667

668

669

670

671

Valkiūnas G, lezhova TA, Loisseau C, Sehgal RNM. 2009. Nested cythochrome b polymerase chain reaction diagnostics detect sporozoites of haemosporidian parasites in peripheral blood of naturally infected birds. Journal of Parasitology 95:1512-1515.

Valkiūnas G, Palinauskas V, Križanauskienė A, Bernotienè R, Kazlauskienè R, lezhova TA. 2013. Further observations on in vitro hybridization of hemosporidian parasites: patterns of ookinete development in Haemoproteus spp. Journal of Parasitology 99:124-136.

Vanstreels RET, Miranda FR, Ruoppolo V, Almeida Reis AO de, Costa ES, Lira Pessôa AR de, Torres JPM, Cunha LST da, Cruz Piuco R da, Valiati VH, González-Acuña D, Labruna MB, Petry MV, Epiphanio S, Catão-Dias JL. 2014. Investigation of blood parasites of pygoscelid penguins at the King George and Elephant Islands, South Shetlands Archipelago, Antarctica. Polar Biology 37:135-139.

Van Rooyen J, Lalubin F, Glaizot O, Christe P. 2013a. Altitudinal variation in haemosporidian parasite distribution in great tit populations. Parasites \& Vectors 6:139 DOI: 10.1186/17563305-6-139.

Van Rooyen J, Lalubin F, Glaizot O, Christe P. 2013b. Avian haemosporidian persistence and coinfection in great tits at the individual level. Malaria Journal 12:40 DOI: 10.1186/1475-2875-1240.

Votypka J, Obornik M, Volf P, Svobodova M. 2002. Trypanosoma avium of raptors (Falconiformes): phylogeny and identification of vectors. Parasitology 125:253-263.

Waldenström J, Bensch S, Kiboi S, Hasselquist D, Ottosson U. 2002. Cross-species infection of blood parasites between resident and migratory songbirds in Africa. Molecular Ecology 11:1545-1554.

Wiersch SC, Lubjuhn T, Maier WA, Kampen H. 2007. Haemosporidian infection in passerine birds from Lower Saxony. Journal of Ornithology 148:17-24.

Wood MJ, Cosgrove CL, Wilkin TA, Knowles SC, Day KP, Sheldon BC. 2007. Within-population variation in prevalence and lineage distribution of avian malaria in blue tits, Cyanistes caeruleus. Journal of Animal Ecology 16:3263-3273.

Zhang Z, Schwartz S, Wagner L, Miller W. 2000. A greedy algorithm for aligning DNA sequences. Journal of Computational Biology 7:203-214. 
Figure 1

Median-joining network of mitochondrial cytochrome b gene lineages of Haemoproteus spp. ( $n=39,463 \mathrm{bp}$ fragment)

Circles represent lineages, and the circle sizes are proportional to the lineage frequencies in the population. One hatch mark represents one mutation. Sampled host species are represented by different colors. Lineage names are noted at the associated circles.

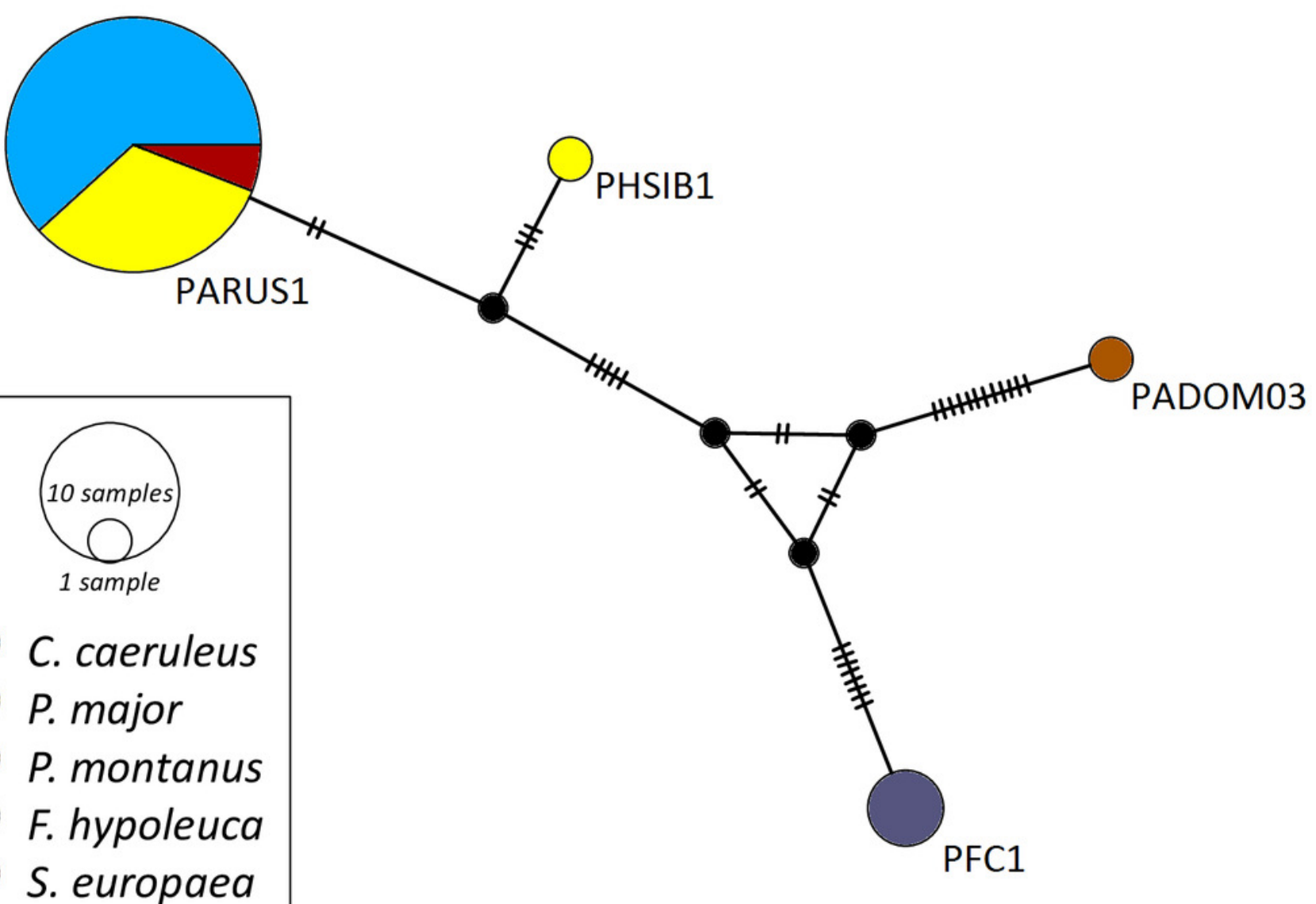


Figure 2

Median-joining network of mitochondrial cytochrome $b$ gene lineages of Plasmodium spp. ( $n=14,440 \mathrm{bp}$ fragment).

Circles represent lineages, and the circle sizes are proportional to the lineage frequencies in the population. One hatch mark represents one mutation. Sampled host species are represented by different colors. Lineage names are noted at the associated circles.

\section{TURDUS1}
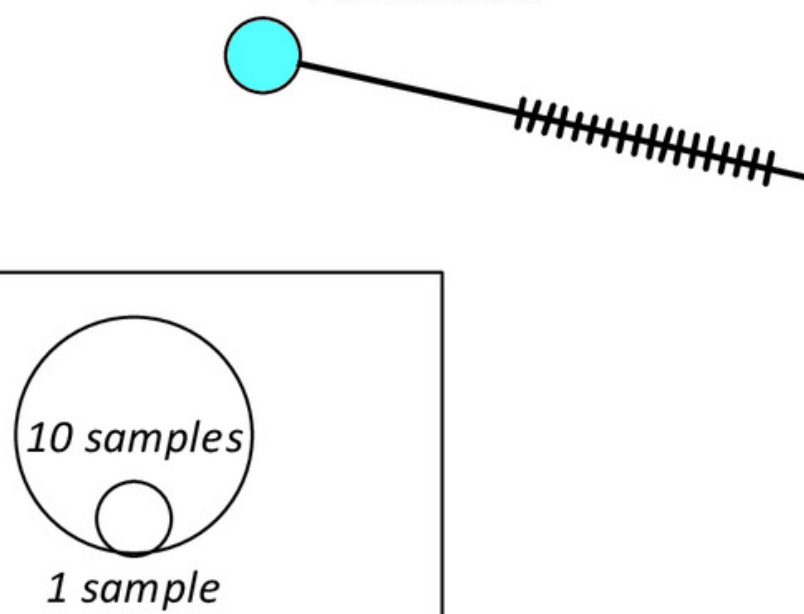

C. caeruleus

P. major

P. montanus

P. ater

GRW11 
Figure 3

Median-joining network of mitochondrial cytochrome b gene lineages of Leucocytozoon spp. ( $n=123,478 b p$ fragment).

Circles represent lineages, and the circle sizes are proportional to the lineage frequencies in the population. One hatch mark represents one mutation. Sampled host species are represented by different colors. Lineage names are noted at the associated circles.

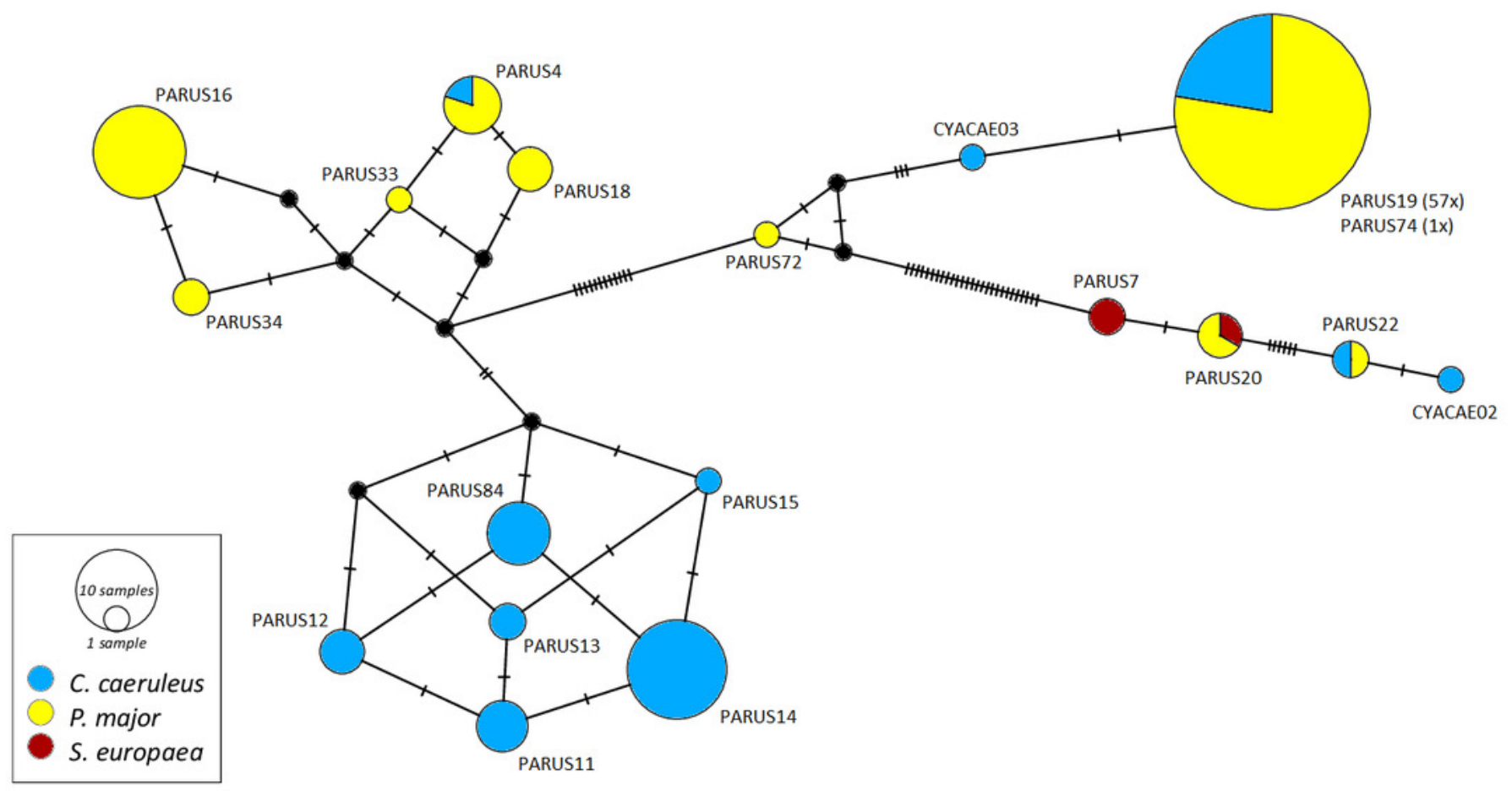




\section{Table $\mathbf{1}$ (on next page)}

Numbers of sampled adult and nestling songbirds.

Sample sizes per sex and parasite genus are given ( $\mathrm{P}=$ Plasmodium spp., $\mathrm{H}=$ Haemoproteus spp., $\mathrm{L}=$ Leucocytozoon spp. and $\mathrm{T}=$ Trypanosoma avium). 


\begin{tabular}{|c|c|c|c|c|c|c|c|}
\hline \multirow[t]{3}{*}{ Species } & \multirow[t]{3}{*}{ Year of sampling } & \multicolumn{6}{|c|}{ Number of specimens ( $\mathrm{n}$ ) } \\
\hline & & \multicolumn{4}{|c|}{ Adult (male/female) } & \multicolumn{2}{|c|}{ Nestling } \\
\hline & & $\mathrm{P}$ & $\mathrm{H}$ & L & $\mathrm{T}$ & L & $\mathrm{T}$ \\
\hline Blue tit (C. caeruleus) & 2017 & $58(30 / 28)$ & $58(30 / 28)$ & $58(30 / 28)$ & $58(30 / 28)$ & $65^{a}$ & $65^{a}$ \\
\hline Great tit (P. major) & $2015 / 2018$ & $32(14 / 18)$ & $32(14 / 18)$ & $142(49 / 93)$ & $68(18 / 50)$ & $57^{\mathrm{b}}$ & $57^{b}$ \\
\hline Coal tits (P. ater) & 2017 & $4(2 / 2)$ & $4(2 / 2)$ & $4(2 / 2)$ & $4(2 / 2)$ & 0 & 0 \\
\hline Eurasian tree sparrow (P. montanus) & $2015 / 2017$ & $10(1 / 9)$ & $10(1 / 9)$ & $10(1 / 9)$ & $10(1 / 9)$ & 0 & 0 \\
\hline European pied flycatcher (F. hypoleuca) & $2015 / 2017$ & $14(2 / 12)$ & $14(2 / 12)$ & $14(2 / 12)$ & $14(2 / 12)$ & 0 & 0 \\
\hline Eurasian nuthatch (S. europaea) & $2015 / 2017$ & $10(3 / 7)$ & $10(3 / 7)$ & $10(3 / 7)$ & $10(3 / 7)$ & 0 & 0 \\
\hline
\end{tabular}

1 age: 16 days

2 b Age: $12-17$ days

3 
Table 2 (on next page)

Primer pairs and their PCR conditions used for blood parasite screening. 


\begin{tabular}{|c|c|c|c|c|c|c|}
\hline Primer pair & Fragment size (bp) & Initial denaturation & $\begin{array}{c}\text { Denaturation } \\
\text { Annealing } \\
\text { Extension }\end{array}$ & Cycles & Final extension & Target gene \\
\hline $\begin{array}{l}\text { HaemF } \\
\text { HaemR2 }\end{array}$ & 480 & $3 \min / 94{ }^{\circ} \mathrm{C}$ & $\begin{array}{l}30 \mathrm{sec} / 94^{\circ} \mathrm{C} \\
30 \mathrm{sec} / 55^{\circ} \mathrm{C} \\
45 \mathrm{sec} / 72^{\circ} \mathrm{C}\end{array}$ & 35 & $10 \min / 72^{\circ} \mathrm{C}$ & Cytochrome b \\
\hline $\begin{array}{l}\text { HaemFL } \\
\text { HaemNR3 }\end{array}$ & 600 & $3 \min / 94^{\circ} \mathrm{C}$ & $\begin{array}{l}30 \mathrm{sec} / 94^{\circ} \mathrm{C} \\
30 \mathrm{sec} / 51^{\circ} \mathrm{C} \\
45 \mathrm{sec} / 72^{\circ} \mathrm{C}\end{array}$ & 35 & $10 \min / 72^{\circ} \mathrm{C}$ & Cytochrome b \\
\hline $\begin{array}{l}\text { TryF } \\
\text { TryR }\end{array}$ & 122 & $10 \min / 95^{\circ} \mathrm{C}$ & $\begin{array}{l}15 \mathrm{sec} / 95^{\circ} \mathrm{C} \\
30 \mathrm{sec} / 56^{\circ} \mathrm{C} \\
60 \mathrm{sec} / 72{ }^{\circ} \mathrm{C}\end{array}$ & 40 & $10 \min / 72^{\circ} \mathrm{C}$ & $18 \mathrm{~S}$ rRNA \\
\hline
\end{tabular}

1 


\section{Table 3 (on next page)}

Haemosporida and Trypanosoma avium prevalence in six songbird species. 


\begin{tabular}{|c|c|c|c|c|c|c|c|c|}
\hline \multirow{2}{*}{$\begin{array}{c}\text { Species } \\
\text { (No. of samples) }\end{array}$} & \multicolumn{2}{|c|}{ Haemoproteus spp. } & \multicolumn{2}{|c|}{ Plasmodium spp. } & \multicolumn{2}{|c|}{ Leucocytozoon spp. } & \multicolumn{2}{|c|}{ Trypanosoma avium } \\
\hline & $\begin{array}{c}\text { positive / } \\
\text { negative }\end{array}$ & $\begin{array}{c}\text { Prevalence } \\
{[\%]}\end{array}$ & $\begin{array}{c}\text { positive / } \\
\text { negative }\end{array}$ & $\begin{array}{c}\text { Prevalence } \\
{[\%]}\end{array}$ & $\begin{array}{l}\text { positive / } \\
\text { negative }\end{array}$ & $\begin{array}{c}\text { Prevalence } \\
{[\%]}\end{array}$ & $\begin{array}{c}\text { positive / } \\
\text { negative }\end{array}$ & $\begin{array}{c}\text { Prevalence } \\
{[\%]}\end{array}$ \\
\hline \multicolumn{9}{|l|}{ C. caeruleus } \\
\hline Adult (58) & $21 / 37$ & 36.2 & $6 / 52$ & 10.3 & $55 / 3$ & 94.8 & $0 / 58$ & 0.0 \\
\hline Nestling (65) & & & & & $0 / 65$ & 0.0 & $0 / 65$ & 0.0 \\
\hline \multicolumn{9}{|l|}{ P. major } \\
\hline Adult (142) ${ }^{a}$ & $13 / 19$ & 40.6 & $7 / 25$ & 21.9 & $110 / 32$ & 77.5 & $0 / 68$ & 0.0 \\
\hline Nestling (57) & & & & & $2 / 55$ & 3.5 & $0 / 57$ & 0.0 \\
\hline \multicolumn{9}{|l|}{ P. ater } \\
\hline Adult (4) & $0 / 4$ & 0.0 & $1 / 3$ & 25.0 & $1 / 3$ & 25.0 & $0 / 4$ & 0.0 \\
\hline \multicolumn{9}{|l|}{ P. montanus } \\
\hline Adult (10) & $1 / 9$ & 10.0 & $2 / 8$ & 20.0 & $0 / 10$ & 0.0 & $0 / 10$ & 0.0 \\
\hline \multicolumn{9}{|l|}{ F. hypoleuca } \\
\hline Adult (14) & $3 / 11$ & 21.4 & $0 / 14$ & 0.0 & $0 / 14$ & 0.0 & $0 / 14$ & 0.0 \\
\hline \multicolumn{9}{|l|}{ S. europaea } \\
\hline Adult (10) & $2 / 8$ & 20.0 & $0 / 10$ & 0.0 & $3 / 7$ & 30.0 & $0 / 10$ & 0.0 \\
\hline Total & $40 / 88$ & 31.3 & $16 / 112$ & 12.5 & $171 / 189$ & 47.5 & $0 / 286$ & 0.0 \\
\hline Nestlings excluded & & & & & 169 / 69 & 71.0 & $0 / 164$ & 0.0 \\
\hline
\end{tabular}

${ }^{a}$ For Haemoproteus spp. and Plasmodium spp. the sample size was 32 and for Trypanosoma avium 68 adult great tits. 


\section{Table 4 (on next page)}

Parasite lineages found in the six songbird species with their closest MalAvi match, the respective accession number and query cover in $\%$. 


\begin{tabular}{|c|c|c|c|c|c|c|c|}
\hline Parasite & $\begin{array}{l}\text { Lineage } \\
\text { (MalAvi) }\end{array}$ & $\begin{array}{c}\text { Accession } \\
\text { Number } \\
\text { (GenBank) }\end{array}$ & $\mathbf{n}$ & $\begin{array}{l}\text { Match } \\
\text { [\%] }\end{array}$ & $\begin{array}{c}\text { Host species (Number } \\
\text { of individuals) }\end{array}$ & $\begin{array}{c}\text { Lineage } \\
\text { prevalence } \\
{[\%]^{+}} \\
\end{array}$ & $\begin{array}{c}\text { Reference } \\
\text { Accession Number }\end{array}$ \\
\hline Haemoproteus $^{\mathrm{a}}$ & PARUS1 & JQ778282 & 34 & 100 & $\begin{array}{l}\text { C. caeruleus (21) } \\
\text { P. major (11) } \\
\text { S. europaea (2) }\end{array}$ & 15.1 & Glaizot et al. 2012 \\
\hline Haemoproteus & PADOM03 & KJ488647 & 1 & 100 & P. montanus (1) & 0.4 & Drovetski et al. 2014 \\
\hline Haemoproteus & PHSIB1 & KJ396634 & 1 & 100 & P. major (1) & 0.4 & Scordato \& Kardish 2014 \\
\hline H. pallidus & PFC1 & JX026899 & 3 & 100 & F. hypoleuca (3) & 1.3 & Valkiūnas et al. 2013 \\
\hline Plasmodium & GRW11 & AY831748 & 3 & 100 & $\begin{array}{l}\text { C. caeruleus (2) } \\
\text { P. montanus (1) }\end{array}$ & 1.3 & Perez-Tris \& Bensch 2005 \\
\hline Plasmodium & SGS1 & AB542064 & 11 & $99-100$ & $\begin{array}{l}\text { C. caeruleus (3) } \\
\text { P. major (7) } \\
\text { P. montanus (1) }\end{array}$ & 4.9 & Ejiri et al. 2011 \\
\hline P. circumflexum & TURDUS1 & KP000842 & 2 & 100 & $\begin{array}{l}\text { C. caeruleus }(1) \\
\text { P. ater }(1)\end{array}$ & 0.9 & Ciloglu et al. 2016 \\
\hline Leucocytozoon $^{\mathrm{b}}$ & PARUS4 & $\mathrm{KJ} 488615$ & 11 & $99-100$ & $\begin{array}{l}\text { P. major }(10) \\
\text { C. caeruleus }(1)\end{array}$ & 4.9 & Mata et al. 2015 \\
\hline Leucocytozoon & PARUS7 & $\mathrm{KJ} 488817$ & 3 & $97-100$ & $\begin{array}{l}\text { P. major (1) } \\
\text { S. europaea (2) }\end{array}$ & 1.3 & Mata et al. 2015 \\
\hline Leucocytozoon & PARUS11 & HM234019 & 5 & $99-100$ & C. caeruleus (5) & 2.2 & Jenkins \& Owens 2011 \\
\hline Leucocytozoon & PARUS12 & HM234020 & 3 & 100 & C. caeruleus (3) & 1.3 & Jenkins \& Owens 2011 \\
\hline Leucocytozoon & PARUS13 & HM234021 & 2 & 100 & C. caeruleus (2) & 0.8 & Jenkins \& Owens 2011 \\
\hline Leucocytozoon & PARUS14 & HM234022 & 15 & 100 & C. caeruleus (15) & 6.7 & Jenkins \& Owens 2011 \\
\hline Leucocytozoon & PARUS15 & HM234023 & 1 & 100 & C. caeruleus (1) & 0.4 & Jenkins \& Owens 2011 \\
\hline Leucocytozoon & PARUS16 & HM234024 & 14 & 100 & P. major (14) & 6.2 & Jenkins \& Owens 2011 \\
\hline Leucocytozoon & PARUS18 & HM234026 & 6 & $99-100$ & $\begin{array}{l}\text { C. caeruleus ( } 2) \\
\text { P. major }(4)\end{array}$ & 2.7 & Jenkins \& Owens 2011 \\
\hline Leucocytozoon & PARUS19 & HM234027 & 67 & $99-100$ & $\begin{array}{l}\text { C. caeruleus }(13) \\
\text { P. major }(53) \\
\text { P. ater }(1)\end{array}$ & 29.8 & Jenkins \& Owens 2011 \\
\hline Leucocytozoon & PARUS20 & KJ488629 & 4 & $99-100$ & $\begin{array}{c}\text { P. major (3) } \\
\text { S. europaea (1) }\end{array}$ & 1.8 & Mata et al. 2015 \\
\hline Leucocytozoon & PARUS22 & HM234031 & 2 & 100 & $\begin{array}{l}\text { P. major }(1) \\
\text { C. caeruleus }(1)\end{array}$ & 0.9 & Jenkins \& Owens 2011 \\
\hline Leucocytozoon & PARUS33 & $J X 867108$ & 2 & 100 & P. major (2) & 0.9 & van Rooyen et al. $2013 \mathrm{~b}$ \\
\hline Leucocytozoon & PARUS34 & JX855049 & 2 & 100 & P. major (2) & 0.9 & van Rooyen et al. $2013 \mathrm{~b}$ \\
\hline Leucocytozoon & PARUS72 & KJ488759 & 3 & 99 & P. major (3) & 1.3 & Mata et al. 2015 \\
\hline Leucocytozoon & PARUS74 & KJ488766 & 9 & 100 & $\begin{array}{c}\text { P. major }(6) \\
\text { C. caeruleus (3) }\end{array}$ & 4.0 & Mata et al. 2015 \\
\hline Leucocytozoon & PARUS84 & KJ488911 & 6 & 100 & C. caeruleus (6) & 2.7 & Mata et al. 2015 \\
\hline Leucocytozoon & CYACAEO2 & MH758695 & 1 & 100 & C. caeruleus (1) & 0.4 & New lineage \\
\hline Leucocytozoon & CYACAE03 & MH758696 & 3 & $98-100$ & $\begin{array}{l}\text { P. major }(1) \\
\text { C. caeruleus }(2)\end{array}$ & 1.3 & New lineage \\
\hline
\end{tabular}


$1+$ Percentage of each lineage among all infected birds $(n=225)$.

2 a 1 sample could be determined as Haemoproteus spp., but could not be assigned to one certain lineage by BLAST against the MalAvi database

3 due to an insufficient sequence quality.

$4 \quad{ }^{b} 10$ samples could be determined as Leucocytozoon spp., but could not be assigned to one certain lineage by BLAST against the MalAvi database

5 due to an insufficient sequence length and quality. 


\section{Table 5 (on next page)}

Overview of publications dealing with Haemosporida and Trypanosoma avium prevalences in great and blue tits sampled in Germany.

Research method, sample sizes, study region and prevalences of the different blood parasites are given ( $\mathrm{P}=$ Plasmodium spp., $\mathrm{H}=$ Haemoproteus spp., $\mathrm{L}=$ Leucocytozoon spp. and $\mathrm{T}=$ Trypanosoma avium). NT = Not tested in the listed study. 


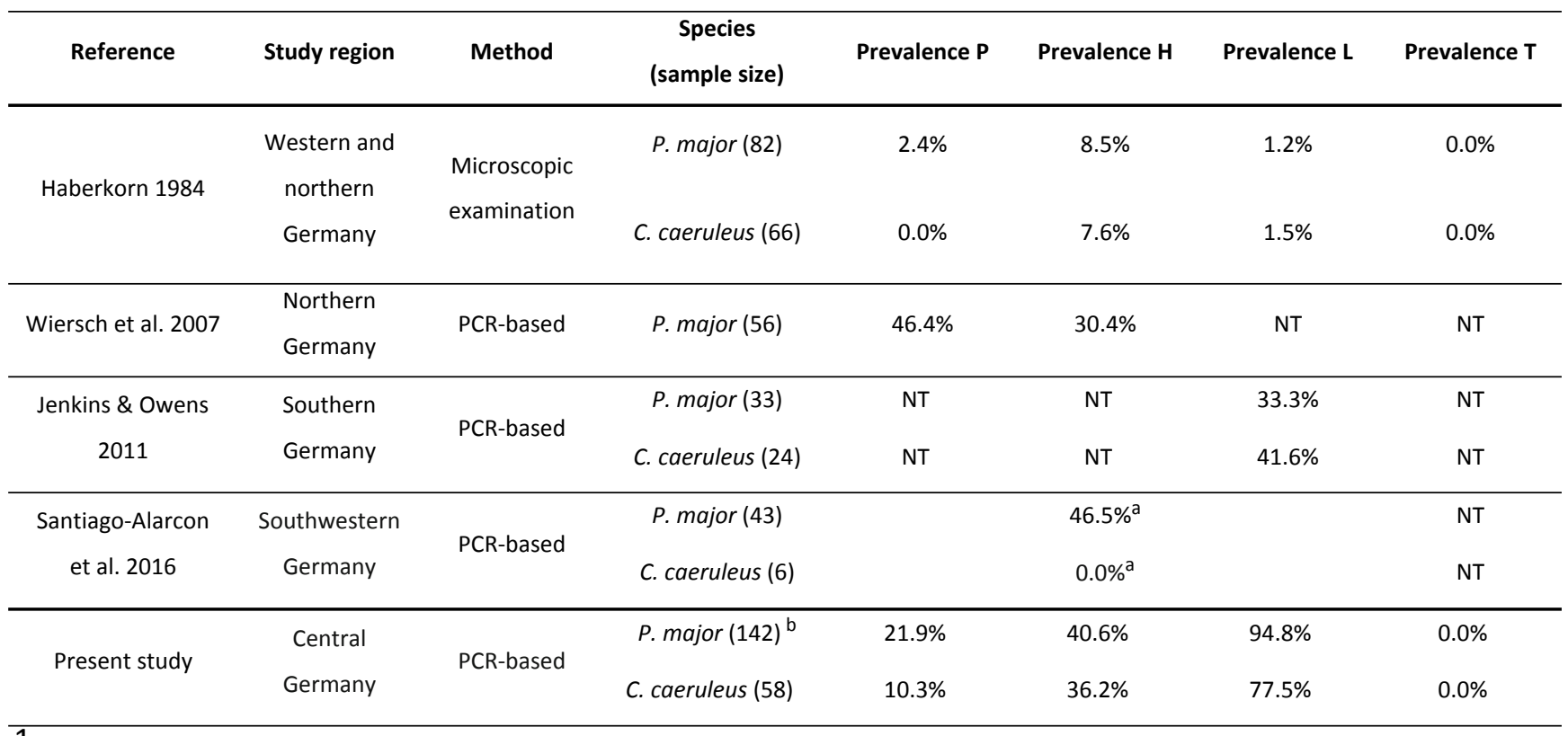

\section{1}

$2{ }^{a}$ Only overall prevalence for the three Haemosprida was given in the publication ( 20 from 43 great tits were infected); no prevalences for the

3 single genera were mentioned.

$4 \quad{ }^{b}$ For Haemoproteus spp. and Plasmodium spp. the sample size was 32 and for Trypanosoma avium 68 adult great tits. 